и растительности (на примере лесостепной и степной зоны). Самара: Самарский университет, 2006. 311 с.

14. Кин Н.О. Флора Бузулукского бора (сосудистые растения). Екатеринбург: УрО РАН, 2009. Т. 2. 283 с.

15. Благовещенский В.В., Пчелкин В.А., Раков Н.С. Определитель растений Среднего Поволжья. Л. Наука, 1984. 392 c.

16. Махлаюк В.П. Лекарственные растения в народной медицине. Киев: Нива России, 1992. 478 с.

17. Кин Н.О., Калмыкова О.Г., Сенатор С.А. Таксономическая структура и эколого-биологические особенности флоры Бузулукского бора // Известия Самарского научного центра РАН. 2014. Т. 16. С. 39-45.

18. Гурулёва Е.А., Корчиков Е.С. К изучению лекарственных растений Красносамарского лесного массива // Структурно-функциональная организация и динамика растительного покрова: матер. Всерос. научно-практич. конф. с международным участием, посвящённой 100-летию со дня рождения д.б.н., проф. В.Е. Тимофеева. Самара: ПГСГА, 2012. С. 24-26.

19. Бузулукский бор: эколого-экономическое обоснование организации национального парка / под ред. А.А. Чибилёва. Екатеринбург: УрО РАН, 2008. Т. 1. $186 \mathrm{c}$.

20. Федеральный закон Российской Федерации от 14 марта 1995 г. №33-Ф3 // Собрание законодательства Российской Федерации. 1995, № 12. ст. 1024. URL: http:// www.zakonrf.info/ (дата обращения: 5.05.2014).

\title{
CONCERNING THE «BUZULUKSKY BOR» NATIONAL PARK FOREST COMMUNITIES MEDICINAL PLANTS
}

(C) 2015

\author{
E.S. Korchikov, candidate of biology sciences, senior lecturer of the \\ Ecology, Botany and Nature Protection Department \\ Samara State University, Samara (Russia) \\ S.A. Pushkina of the Ecology, Botany and Nature Protection Department \\ Samara State University, Samara (Russia)
}

\begin{abstract}
Annotation. The are 266 medicinal vascular plants from 181 genera, 64 families, 5 phylum (Lycopodiophyta, Equisetophyta, Pteridophyta, Pinophyta, Magnoliophyta) in the «Buzuluksky Bor» national park. 67 species of medicinal vascular plants from 59 genera, 27 families and 4 phylum grows in forest communities, which are the most widespread such plants as Chelidonium majus L., Convallaria majalis L., Fallopia convolvulus (L.) A. Löve, Polygonatum odoratum (Mill.) Druce, Taraxacum officinalis L. and Pinus sylvestris L. Increasing number of medicinal plants has a considerable projective covering in oak forests. 30 species of medicinal plants, most of all their share in the maple forests are specific to a certain type of forest communities. The greatest similarities of specific structure of medicinal plants are oak and birch communities. The number of medicinal plants in forest communities decreases among: oak forests $(35$ species $)>$ birch forests $(33$ species $)>$ pine forests $(30$ species $)>$ maple forests $(29$ species $)$. With increase in a gigrotope and reduction of a trofotope in community of the national park «Buzuluksky Bor» located in a forest-steppe zone a variety of medicinal plants increases, however the heliotope has no significant impact on number of medicinal plants. In the territory of national park «Buzuluksky Bor» it is recommended to collect herbs only in a recreational zone and a zone of informative tourism, and in oak and birch forests. Convallaria majalis, Pteridium aquilinum, Aegopodium podagraria, Polygonatum odoratum are less vulnerable when collecting medicinal raw materials.
\end{abstract}

Keywords: medicinal plants; vascular plants; «Buzuluksky Bor»; national park; Samara Region; Orenburg Region; phytocenological confinedness.

\section{УДК 504.5:631.42:661.152(470.57) \\ ХИМИЧЕСКОЕ ЗАГРЯЗНЕНИЕ ПОЧВ ТЕРРИТОРИИ, ПРИЛЕГАЮЩЕЙ К ОАО «МЕЛЕУЗОВСКИЕ МИНЕРАЛЬНЫЕ УДОБРЕНИЯ»}

(C) 2015

К.А. Косачёва, студентка кафедры экологии и природопользования

Оренбургский государственный университет, Оренбург (Россия)

М.Ю. Гарицкая, кандидат биологических наук, доцент кафедры экологии и природопользования Оренбургский государственныий университет, Оренбург (Россия)

А.И. Байтелова, кандидат технических наук, доцент кафедры экологии и природопользования Оренбургский государственный университет, Оренбург (Россия)

Л.А. Пикус, студентка кафедры экологии и природопользования Оренбургский государственный университет, Оренбург (Россия)

Аннотация. Загрязнение окружающей среды промышленными предприятиями, приводящее к ее деградации и наносящее ущерб здоровью населения, остается актуальной экологической проблемой, имеющей социальное и экономическое значение. В настоящее время все больше земель подвержены техногенным факторам, которые изменяют химический состав почвы. Все это является результатом использования в сельском хозяйстве разнообразных пестицидов, минеральных удобрений, стимуляторов роста растений. Но, помимо этого, немаловажную роль в загрязнении почв имеют промышленные выбросы.

В данной статье рассматривается влияние предприятия по производству минеральных удобрений - ОАО «Мелеузовские минеральные удобрения» - на качество почв и экологическую ситуацию, складывающуюся на прилегающей территории. По функциональному назначению данная территория является зоной выращивания сельскохозяйственных культур. Весьма не безопасным является то, что данный участок расположен в границах санитарно-защитной зоны предприятия. Мониторинг почв уже на ранних стадиях позволяет отслеживать начавшиеся изменения в окружающей среде. Для оценки экологического состояния исследуемой территории проводилось определение показателя химического загрязнения почв, отобранных на различных расстояниях от предприятия, и ранжирование по степени экологического неблагополучия. Результаты проведенных анализов показали, что наибольшие концентрации загрязняющих веществ содержатся в образцах почв, взятых на минимальном удалении от предприятия. Это подтверждает воздействие на территорию приоритетных выбросов 
химзавода.

Ранжирование по показателю химического загрязнения почв свидетельствует о том, что территорию, прилегающую к ОАО «Мелеузовские минеральные удобрения», на всех исследуемых расстояниях, следует отнести к зоне с критической экологической ситуацией.

Ключевые слова: концентрация; показатель химического загрязнения; коэффициент концентрации; ранжирование; исследуемая территория; экологическая ситуация.

В настоящее время все проблемы окружающей среды можно свести к человеку, так как любое отрицательное воздействие на среду исходит от человека как субъекта хозяйственной деятельности, производителя, потребителя, носителя технического прогресса, да и просто как жителя планеты [1, с. 16].

Современные производства

зачастую характеризуются весьма сложной технологией, большим количеством операций, сопровождающихся выбросами и сбросами загрязняющих веществ в окружающую среду, возникновением целого ряда отходов, часть из которых используется или складируются, либо теряется с отходящими газами, сточными водами и твердыми продуктами [2, с. 35]. Попадая в природную среду, техногенные вещества и энергия (в виде отходов) перераспределяются за счет миграции, трансформации и аккумуляции в различных компонентах биосферы $[3$, c.303].

Техногенные факторы уже существенно изменили и продолжают изменять качество почв. Как правило, главным источником химического загрязнения почв служат: отходы сельхозпроизводства, отходы переработки сельхозпродуктов, минеральные удобрения, химические и нефтехимические предприятия, автотранспорт, пестициды и др. [4,c.7]. Но, помимо этого, большое влияние на качество почв оказывают атмосферные выпадения в радиусе деятельности промышленных предприятий [5,c.45]. К примеру, когда выпадают осадки, загрязняющие вещества из воздуха «вымываются» и переносятся на подстилающую поверхность. Таким образом, выбросы токсичных веществ оказывают негативное воздействие не только на атмосферу, но и на почвы $[6$, с. 8$]$.

Согласно Государственному докладу о состоянии окружающей среды Республики Башкортостан, объем выбросов загрязняющих веществ в атмосферу от стационарных источников в городе Мелеуз в 2014 году составил 2,2 тыс.т. Одним из основных загрязнителей атмосферы города является ОАО «Мелеузовские минеральные удобрения〉 $(0,985$ тыс.т $)$ [7, с. 72$]$.

Анализ современного состояния производства и применения минеральных удобрений показалувеличение производственных мощностей и соответственно негативного влияния на среду обитания, различную степень напряженности санитарной ситуации в районах их размещения, отсутствие четкой системы надзора за оборотом агрохимикатов, а также системы мониторинга при их производстве и применении [9, с. 7]. В 2012 году, например, из-за увеличения объемов производства минеральных удобрений произошло увеличение объемов выбросов от химзавода на 0,370 тыс.т. или $43 \%$. К тому же утечки летучих соединений не включают в отчеты о выбросах, что ведет к недооценке общего количества выбросов на предприятии [8, с. 15].

Таким образом, проблема воздействия производства минеральных удобрений на атмосферный воздух города, a, следовательно, и на почвы прилегающих территорий, является актуальной.

Для экологического состояния почв имеет значение поглощение как необходимых для растений питательных элементов, так и загрязняющих веществ $[10$, с. 98]. Защитить сопредельные с почвой среды от загрязняющих веществ почва может, только поглотив эти вещества и удерживая их в слабо подвижном состоянии. Связывая загрязняющие вещества физически и химически, почва служит своеобразным фильтром для загрязняющих веществ. За счет этого предотвращается или ограничивается поступление этих веществ и в природные воды, и в растения, и далее по пищевым цепочкам - в организм животных и человека $[11$, с. 36$]$. Устойчивость экосистемы к загрязняющим веществам обеспечивается, прежде всего, буферной способностью почв [12, с.22].

Благодаря своим особенностям почва является стабильным и наиболее объективным индикатором техногенного загрязнения, в отличие от воды и воздуха [13,c.125]. Поэтому мониторинг почв уже на ранних стадиях позволяет отслеживать начавшиеся изменения и предупреждать их последствия, а интегральная оценка состояния почвенного тела представляет научный и практический интерес [14, с.123].

Целью работы являлось определение показателя химического загрязнения почв и ранжирование по степени экологического неблагополучия территории, прилегающей к ОАО «Мелеузовские минеральные удобрения».

Объектом исследования являлась территория, расположенная северо-восточнее от основной промплощадки ОАО «Мелеузовские минеральные удобрения». Данная промплощадка предприятия расположена в Мелеузовском районе Республики Башкортостан в 3,5 км северо-восточнее г. Мелеуза, на бывших землях совхоза «Арслановский». Рельеф здесь представляет открытую слабопересеченную местность $[15$, c. 64$]$.

Основные производства данного предприятия включают цех слабой азотной кислоты и аммиачной селитры[16]. Приоритетными выбросами являются углерода оксид, аммоний нитрат, аммиак и азота диоксид. С поверхности накопителя кислой воды имеющегося отвала фосфогипса выделяются фториды газообразные.

Исследуемая территория и сегодня является зоной сельскохозяйственного назначения. Она находится в пределах санитарно-защитной зоны завода, что не соответствует требованиям СанПиН 2.2.1/2.1.1.1200-03 (новая редакция) [17].

Для оценки степени химического загрязнения образцы почвы отбирались в северо-восточном направлении на расстоянии $20,720,1020,1520$ и 2020 м от ограждения территории основной промплощадки. Юго-западное направление является приоритетным по среднегодовой розе ветров.

По общепринятым методикам и по ГОСТ 26488-85, ПНДФ 16.1:2:2.2:3.51-08, МУ М. 1993г. в лаборатории был проведен анализ взятых проб почвы по следующим показателям: $\mathrm{pH}$ почвенной вытяжки, содержание кислотообразующих веществ, ионов кальция, магния и аммония (табл.1). Результаты проведенных анализов приведены в таблице 1 .

Согласно полученным данным можно сделать вывод о том, что ионы аммония являются преобладающими во всех образцах почв. С увеличением расстояния от источника загрязнения их содержание в почве увеличивается, но максимум достигнут на расстоянии 1020 метров от территории промплощадки. Такой результат может быть объяснен тем, что для трансформации ионов аммония в атмосфере и их последующего осаждения на почву требуется время [18, c. 32]. 
Таблииа 1 ситуацией, то есть закисления почв здесь не происходит.

Кониентрация загрязняющих веществ в почве

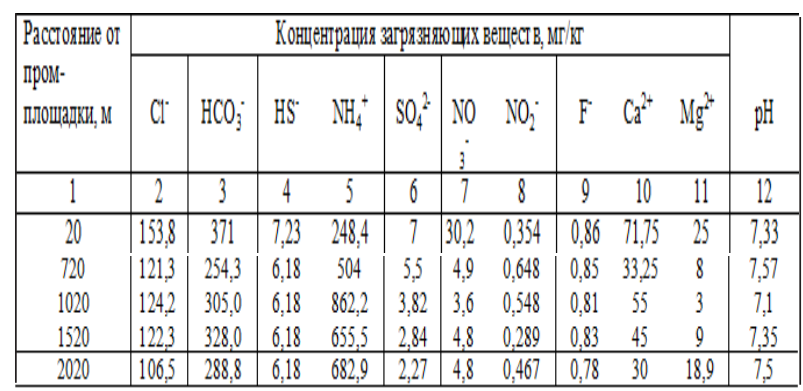

Среди кислотообразующих веществ во всех пробах приоритетными являются хлорид- и гидрокарбонатионы, их максимальные концентрации 153,8 и 371 мг/ кг соответственно наблюдаются на расстоянии 20 метров от промплощадки. При этом с удалением от нее наблюдается уменьшение концентраций этих веществ в почве: в 1,4 раза по хлоридам и 1,3 раза по гидрокарбонатам.

Максимальное содержание нитрат-ионов также наблюдается в образцах почв, взятых на расстоянии 20 метров и составляет 30,2 мг/кг, в остальных пробах их содержание колеблется в пределах от 3,6 до 4,9 мг/кг. Такая разница в концентрациях напрямую подтверждает воздействие на территорию приоритетных выбросов химзавода и уменьшение этого воздействия с удалением от него. Содержание нитратов уменьшается с увеличением расстояния в 6,4 раза.

Концентрация фторидов в образцах находится на уровне $0,78-0,86$ мг/кг. На расстоянии 20 метров наблюдается и максимальная концентрация соединений серы и составляет по гидросульфид-ионам 7,23 мг/кг, а по сульфат-ионам - 7 мг/кг. При увеличении расстояния от источника их концентрация снижается в 1,2 и 3,1 раза соответственно.

Исследование почв на выбранном участке показало, что основная часть почв здесь характеризуется нейтральной или близкой к ней реакцией среды, значения рН колеблются от 7,1 до 7,57.

О химическом загрязнении почв судили не только по концентрации загрязняющих веществ, но и по коэффициенту концентрации и показателю химического загрязнения (ПХЗП) [19, с. 10] (табл.2).

Расчеты коэффициента концентрации и показателя химического загрязнения осуществлялись относительно значений фоновых концентраций почв, отобранных на территории национального парка «Башкирия». Полученные результаты сведены в таблицу 2.

Исходя из данных, представленных в таблице, можно сделать вывод о том, что наибольшее значение коэффициента концентрации во всех пробах почв имеют ионы аммония. Максимальное превышение фона по ионам аммония, равное 13,6 раз, наблюдается на расстоянии 1020 метров от промплощадки.

Табличуа 2

Коэффициент концентрации и показатель химического загрязнения почв

\begin{tabular}{|c|c|c|c|c|c|c|c|c|c|c|c|}
\hline \multirow{2}{*}{$\begin{array}{l}\text { Расстояние от } \\
\text { пром- } \\
\text { плошадки, м }\end{array}$} & \multicolumn{10}{|c|}{ Коэффициент концентрации загрязняющих веществ } & \multirow{2}{*}{$\Pi \times 3_{n}$} \\
\hline & $\mathrm{Cl}^{-}$ & $\mathrm{HCO}_{3}^{\circ}$ & HS & $\mathrm{NH}_{4}^{+}$ & $\mathrm{SO}_{4}^{2 \cdot}$ & $\mathrm{NO}_{3}^{-}$ & $\mathrm{NO}_{2}^{\circ}$ & $\mathrm{F}$ & $\mathrm{Ca}^{2+}$ & $\mathrm{Mg}^{2+}$ & \\
\hline 20 & 9,9 & 1,2 & 3,1 & 3.9 & 0.9 & 1.9 & 0,06 & 0,31 & 0,7 & 0,98 & 22.94 \\
\hline & 7,8 & 0 & & & & & & & & & 21,2 \\
\hline & 7,9 & 1.01 & 2,7 & 136 & 0,5 & 023 & 0.0 & 0,29 & 0,6 & & 26,99 \\
\hline 1520 & 7,8 & 1.08 & $\frac{2,7}{2,7}$ & 103 & 0,4 & 0,3 & 0,05 & 0,3 & 0,5 & 0,4 & 23,9 \\
\hline 2020 & 6.8 & 0,96 & $\frac{2,7}{2,7}$ & 10.8 & 0,3 & 0,3 & 0.08 & 0,28 & 0,3 & 0,7 & 23,2 \\
\hline
\end{tabular}

Ранжирование по значению $\mathrm{pH}$ почвенной среды показало, что территорию, прилегающую к ОАО «Мелеузовские минеральные удобрения», на всех исследуемых расстояниях можно отнести к зоне с
Ранжирование по показателю химического загрязнения почв свидетельствует о том, что исследуемую территорию на всех расстояниях от промплощадки предприятия, следует отнести к зоне c критической экологической ситуацией. При этом наиболее благоприятная ситуация складывается на расстоянии 720 метров, а наименее благоприятная - на расстоянии 1020 метров от предприятия. В дальнейшем при увеличении расстояния показатель химического загрязнения снижается, что свидетельствует об улучшении экологической обстановки на данной территории.

Таким образом, деятельность завода по производству минеральных удобрений влияет на качество почв и экологическую обстановку исследуемой территории, что свидетельствует о недопустимости ее использования для выращивания сельскохозяйственных культур, используемых для производства продуктов питания.

\section{СПИСОК ЛИТЕРАТУРЫ}

1. Голицын А.Н. Основы промышленной экологии / А.Н. Голицын. М.: ИРПО, 2002. - 240 с.

2. Байтелова А.И. Источники загрязнения среды обитания: учеб. пособие для вузов / А. И. Байтелова, М.Ю. Гарицкая, В. Ф. Куксанов; М-во образования и науки Рос. Федерации, Федер. агентство по образованию, Гос. образоват. учреждение высш. проф. образования "Оренбург. гос. ун-т". - Оренбург : ГОУ ОГУ, 2009. -190с.

3. Николайкин Н.И. Экология: учеб.для вузов / Н.И. Николайкин, О.П. Мелехова. - 6-е изд., испр. - М.: Дрофа, 2008. - 622 с.: ил.

4. Волкова И.Н., Кондакова Г.В. Экологическое почвоведение: Лабораторные занятия для студентовэкологов (бакалавров): Метод. указания / Сост. И.Н. Волкова, Г.В. Кондакова; Яросл. гос. ун-т. Ярославль, 2002. 35 с.

5. Байтелова А.И. Промышленная экология: учеб. пособие / А. И. Байтелова, М. Ю. Гарицкая, О.В. Чекмарева; М-во образования и науки Рос. Федерации, Федер. агентство по образованию, Гос. образоват. учреждение высш. проф. образования "Оренбург. гос. ун-т". - Оренбург : ГОУ ОГУ, $2010-145$ c.

6. Байтелова, А. И. Оценка и прогноз качества атмосферного воздуха урбанизированной территории, прилегающей к сложным площадным источникам выбросов примесей: автореф. дис. канд. техн. наук: 25.00.36 / А. И. Байтелова. - Оренбург : [Б. и.], 2004.- 18 с.

7. Государственный доклад «О состоянии природных ресурсов и охраны окружающей среды Республики Башкортостан» в 2014 году //Экологический портал РБ, 2010 г. - Режим доступа: http://www.ecorb.ru.

8.БайтеловаА.И.Источникизагрязнениятехносферы: методические указания для студентов, обучающихся по программам высшего профессионального образования по направлению подготовки 280700.62 Техносферная безопасность / А. И. Байтелова, М. Ю. Гарицкая, О.В. Чекмарева; М-во образования и науки Рос. Федерации, Федер. гос. бюджет. образоват. учреждение высш. проф. образования "Оренбург. гос. ун-т", Каф. экологии и природопользования. - Оренбург : Университет, 2013.- 53 с.

9. Механтеева Е.В. Профилактика негативного воздействия производства минеральных удобрений на окружающую среду и здоровье населения: автореф. дис. докт. мед. наук: 14.00.07/ Е.В. Механтеева. М.:2008. - $48 \mathrm{c}$.

10. Механтеева Е.В. Профилактика негативного воздействия производства минеральных удобрений на окружающую среду и здоровье населения: автореф. дис. докт. мед. наук: 14.00.07/ Е.В. Механтеева. М.:2008. - 48 c. 
11. Мудрый, И. В. Влияние химического загрязнения санитарного врача РФ от 25 сентября 2007 г. N 74 почвы на здоровье населения/ И. В. Мудрый // Гигиена и санитария,2008. - № 4. - С. 32-37.

12. Мотузова Г.В., Безуглова О.С. Экологический мониторинг почв :учебник/Г.В. Мотузова, О.С. Безуглова. М.: Академический Проект; Гаудеамус, 2007. 237c.

13. Гарицкая М.Ю. Оценка экологического состояния территории, прилегающей к Сакмарской ТЭЦ / М. Ю. Гарицкая, О. Н. Нечитайло // Вестник Оренбургского государственного университета. - 2005. №9. - С. 125- 128.

14. Орлов Д.С. Химия почв / Д.С. Орлов, Л.К. Садовников, Н.И. Суханова. М.: Высш. шк., 2006. -558 c.

15. Валеева Т.Н. Этапы большого пути ОАО «Мелеузовские минеральные удобрения» / Т.Н. Валеева, Т.И. Севостьянова. - г. Уфа: ООО ИПК «Лаки», 2006.

16. Официальный сайт ОАО «Мелеузовские минеральные удобрения». - Режим доступа: www.oaommu.ru.

17. Постановление Главного государственного "О введении в действие новой редакции санитарноэпидемиологических правил и нормативов СанПиН 2.2.1/2.1.1.1200-03 “Санитарно-защитные зоны и санитарная классификация предприятий, сооружений и иных объектов": Зарегистрировано в Минюсте РФ 25 января 2008 г. - Система ГАРАНТ. - Режим доступа: http://base.garant.ru.

18. Хомяков, Д. М. Эколого-экономические вопросы производства и потребления минеральных удобрений в России / Д. М. Хомяков, Б. В. Левин // ЭКиП: Экология и промышленность России, 2005. - N 1. - С. 30-33.

19. Методические указания к лабораторным работам по дисциплине специализации "Химия окружающей среды”/Т. Ф. Тарасова, О. В. Малыхина, М. Ю. Гарицкая. - Оренбург : ОГУ, 2001. - 16 с.

20. Методика "Критерии оценки экологической обстановки территорий для выявления зон чрезвычайной экологической ситуации и зон экологического бедствия" (утв. Минприроды РФ 30.11.1992)// КонсультантПлюс: справочная правовая система 1992-2015. - Режим доступа: http://www.consultant.ru.

\title{
CHEMICAL CONTAMINATION OF SOILS TERRITORIES ADJACENT TO THE JSC «MELEUZ MINERAL FERTILIZERS»
}

\author{
C.A. Kosacheva, a student at the Department of Ecology and Environmental Sciences \\ Orenburg State University, Orenburg (Russia) \\ M.Y. Garitskaya, candidate of biological sciences, Associate Professor, Department of Ecology and \\ Environmental Sciences \\ Orenburg State University, Orenburg (Russia) \\ A.I. Baitelova, candidate of biological sciences, Associate Professor, Department of Ecology and \\ Environmental Sciences \\ Orenburg State University, Orenburg (Russia)
}

L. A. Pikus, a student at the Department of Ecology and Environmental Sciences

Orenburg State University, Orenburg (Russia)

\begin{abstract}
Environmental pollution by industrial enterprises, leading to its degradation and impairing the health of the population remains an urgent concern of environmental social and economic importance. At present, more and more land is subject to man-made factors that alter the chemical composition of the soil. All this is the result of agricultural use of various pesticides, fertilizers, plant growth stimulants. But beyond that, many an important role in soil pollution are industrial emissions.

This article examines the impact of the enterprise for the production of mineral fertilizers - JSC «Meleuz Minetal Fertilizers» - the quality of soil and environmental situation developing at a location nearby. On a functional purpose, this area is an area of growing crops. Not very safe is that this site is located within the boundaries of the sanitary protection zone. Monitoring of soil at an early stage allows you to track incipient changes in the environment. To assess the ecological status of the study area were determined indicator of chemical pollution of soils sampled at different distances from the plant, and the ranking according to the degree of ecological trouble. The results of the analysis showed that the highest concentrations of pollutants found in soil samples taken at the minimum distance from the plant. This confirms the impact on the territory of priority chemical plant emissions.

Ranking in terms of chemical contamination of soils indicates that the territory adjacent to the JSC «Meleuz Mineral Fertilizers»», at all distances studied, should be referred to an area with critical ecological situation.

Keywords: concentration; the rate of chemical contamination; concentration ratio; ranking; the study area; the environmental situation.

\section{УДК 574.2 \\ ПОЛУЧЕНИЕ ЭКОЛОГИЧЕСКИ БЕЗОПАСНОЙ ПРОДУКЦИИ КОНЕВОДСТВА НА ОСНОВЕ КОМПЛЕКСНОГО ИССЛЕДОВАНИЯ СОДЕРЖАНИЯ ТЯЖЕЛЫХ МЕТАЛЛОВ В ПОЧВЕННОМ ПОКРОВЕ БАШКОРТОСТАНА}

(C) 2015
\end{abstract}

А.Б. Латыпов, кандидат биологических наук, доцент кафедры технологического образования Бирский филиал Башкирского государственного университета, Бирск(Россия)

Р.Я. Сафиханов, кандидат биологических наук, доцент, заместитель директора по учебной работе;

Аннотащия. Исследования различных природно - сельскохозяйственных зон Республики Башкортостан на содержание тяжелых металлов (ТМ) в почвах и кормах позволили оценить их биоаккумуляцию, влияние на организм лошадей и выявление районов с приемлемыми условиями для содержания и получения экологически безопасной продукции коневодства.

Для этого предполагается интенсификация продуктивного коневодства - организация на всех конефермах республики производства конины и кумыса, нагула и откорма лошадей, расширение ассортимента продуктов из конины и широкое приобщение населения к конному спорту. Мясо конины ценится, прежде всего, за наличие в нем полноценных белков, витаминов группы В, особенно ниацина. Оно содержит большое количество железа и 